\title{
Kinematic gait analyses in healthy Golden Retrievers ${ }^{1}$
}

\author{
Gabriela C.A. Silva², Mariana Trés Cardoso ${ }^{3}$, Thais P. Gaiad ${ }^{4}$, Marina P. Brolio ${ }^{5}$, Vanessa \\ C. Oliveira ${ }^{3 *}$, Antonio Assis Neto ${ }^{5}$, Daniele S. Martins ${ }^{3}$ and Carlos E. Ambrósio ${ }^{3}$
}

\begin{abstract}
Silva G.C.A., Cardoso M.T., Gaiad T.P., Brolio M.P., Oliveira V.C., Assis Neto A., Martins D.S. \& Ambrósio C.E. 2014. Kinematic gait analyses in healthy Golden Retrievers. Pesquisa Veterinária Brasileira 34(12):1265-1270. Departamento de Medicina Veterinária, Faculdade de Zootecnia e Tecnologia Alimentar, Universidade de São Paulo, Campus de Pirassununga, Av. Duque de Caxias Norte 225, Pirassununga, SP 13635-900, Brazil. E-mail: van.oliveira@usp.br

Kinematic analysis relates to the relative movement between rigid bodies and finds application in gait analysis and other body movements, interpretation of their data when there is change, determines the choice of treatment to be instituted. The objective of this study was to standardize the march of Dog Golden Retriever Healthy to assist in the diagnosis and treatment of musculoskeletal disorders. We used a kinematic analysis system to analyse the gait of seven dogs Golden Retriever, female, aged between 2 and 4 years, weighing 21.5 to $28 \mathrm{~kg}$, clinically normal. Flexion and extension were described for shoulder, elbow, carpal, hip, femorotibialis and tarsal joints. The gait was characterized lateral and had accepted hypothesis of normality for all variables, except for the stance of hip and elbow, considering a confidence level of $95 \%$, significance level $\alpha=0.05$. Variations have been attributed to displacement of the stripes during movement and the duplicated number of reviews. The kinematic analysis proved to be a consistent method of evaluation of the movement during canine gait and the data can be used in the diagnosis and evaluation of canine gait in comparison to other studies and treatment of dogs with musculoskeletal disorders.
\end{abstract}

INDEX TERMS: Biomechanics, gait analysis, kinematics, canine gait.

RESUMO.- [Análise cinemática da marcha de cães Golden Retriever saudáveis.] A análise cinemática relaciona-se com o movimento relativo entre corpos rígidos e encontra aplicação na análise da marcha e de outros movimentos do corpo. A interpretação de seus dados, quando há alteração, determina a escolha do tratamento a ser instituído. 0 objetivo deste estudo foi padronizar a marcha do cão Gol-

\footnotetext{
${ }^{1}$ Received on Abril 9, 2014.

Accepted for publication on November 4, 2014.

${ }^{2}$ Centro Universitário Italo Brasileiro, Av. Joao Dias 2046, Santo Amaro, SP 04724003, Brazil.

${ }^{3}$ Departamento de Medicina Veterinária, Faculdade de Zootecnia e Engenharia de Alimentos, USP, Campus de Pirassununga, Avenida Duque de Caxias Norte 225, Pirassununga, SP 13635-900, Brazil. *Corresponding author: van.oliveira@usp.br

${ }^{4}$ Departamento de Fisioterapia, Universidade Federal dos Vales do Jequitinhonha e Mucuri, Campus JK, Rodovia MG-367 Km 583, 5000, Alto da Jacuba, Diamantina, MG 39100-000, Brazil.

${ }^{5}$ Departamento de Cirurgia, Faculdade de Medicina Veterinária e Zootecnia, Universidade de São Paulo (USP), Av. Orlando Marques de Paiva 85, São Paulo, SP 05508-270.
}

den Retriever saudável visando auxiliar no diagnóstico e tratamento de afecções músculo esquelética. Neste estudo utilizou-se um sistema de análise cinemática para analisar a marcha de sete cães da raça Golden Retriever, fêmeas, idade entre 2 e 4 anos, peso variando de 21.5 a $28 \mathrm{~kg}$, clinicamente sadias. Dados morfométricos foram coletados para descrever a população estudada. Variáveis de tempo e distâncias foram mensuradas para descrever a marcha, movimentos de flexão e extensão foram descritos para as articulações do ombro, cubital, cárpica, do quadril, femorotibial e társica. A marcha foi caracterizada lateral e teve hipótese de normalidade aceita para todas as variáveis, exceto para o apoio de quadril e apoio de cúbito, considerando um grau de confiança de $95 \%$, ou seja, nível de significância $\alpha=0.05$. As variações foram atribuídas ao deslocamento das tarjas durante o movimento e ao repetido número de avaliações. A análise cinemática provou ser um consistente método de avaliação do movimento durante a marcha canina e os dados obtidos podem ser utilizados no diagnóstico e na comparação em avaliações de marcha para outros estudos e tratamento de cães com afecções musculoesqueléticas. 
TERMOS DE INDEXAÇÃO: Biomecânica, análise da marcha, cinemática e marcha canina.

\section{INTRODUCTION}

Veterinary science in the study of locomotion is essential to establish methods for the treatment of disorders of the locomotors apparatus (Wingfield \& Stead 1993, Poy et al. 2000).

The dogs were studied exclusively the Golden Retriever for presenting increasing incidence of musculoskeletal disorders, is a widely used canine model of Duchenne muscular dystrophy (DMD) that has been addressed in several studies (Gaiad 2009, Gerger et al. 2010, Abreu et al. 2012, Kane et al. 2013).

Golden retriever dog is showing increasing incidence of musculoskeletal disorders such a hip dysplasia (Paster et al. 2005). According to official OFA-Orthopaedic Foundation for Animals (OFA), Golden Retriever dogs occupy the 32nd positions in the ranking of breeds affected by hip dysplasia.

Gait is the most effective form of locomotion, therefore, to a better understanding, is divided into events and these divided into phases (Tokuriki 1973).

According to official Orthopaedic Foundation for Animals (OFA), Golden Retriever dogs occupy the 32nd positions in the ranking of breeds affected by hip dysplasia form of locomotion, therefore, to a better understanding. Gait is the most effect form of locomotion, therefore, to a better understanding, is divided into events and these divided into phases (Tokuriki 1973).

A study about kinematic pattern in clinically normal Labrador and Rottweiler dogs indicated that both breeds have similar kinematic patterns, but there are magnitude differences, especially of the elbow and stifle joints. Therefore, each breed should have a specific database (Agostinho et al. 2011).

Kinematic analysis of gait canine has been addressed by several authors (Poy et al. 2000, Marsolais et al. 2003, Nielsen et al. 2003, Colborne et al. 2005, Foss et al. 2013, Torres et al. 2013). However, none addresses the gait in golden retriever healthy dog.

This study addresses the variables of gait of golden retriever healthy dogs as assessment of step length and stride the fore and hind limbs, as well as the height of the last of each member during gait, joint angle of peak movements flexion-extension of shoulder joint, elbow, hip, femorotibial and tarsal during periods of balance, stance and propulsion. Therefore, we intend to establish a pattern of normal gait, assisting the diagnosis of muscle-skeletal and neurological diseases, help in choosing the most appropriate treatment, and contribute to a better understanding of the complex mechanism that anoint the movements of locomotion.

The objective of this study was to standardize the march of Dog Golden Retriever Healthy aiming to assist in the diagnosis and treatment of musculoskeletal disorders.

\section{MATERIALS AND METHODS}

Animals. The study was conducted in the Biomechanics Laboratory of The Faculty of Sports of the University of Sao Paulo. An Experimental protocol 946/2006 was authorized by the Bioethics
Committee of the School of Veterinary Medicine, University of Sao Paulo (USP), Brazil.

Seven golden retriever female dogs, aged between 2 and 4 years, weights varying from twenty one to twenty eight $\mathrm{kg}$, were submitted to the physical and radiological evaluation, exempt of neurological and muscle- skeletal affections and, without description of lameness in any one of the four members. The animals were radiographed in the Veterinarian Hospital of University of Sao Paulo.

Biometry. The animals were evaluated individually, in station position. The variables of measurement were the lengths of the corporal segments, circumference of the thorax, and height of animal. All of biometrics data were measured using metric tape.

It was also measured, utilizing as reference the same anatomic points know in humans. The height of each animal was measured from the scapula to fifth metacarpal. Each segment was evaluated three times to minimize possible measure errors, the average of the three measures was considered for the analysis.

Kinematic. A digital camera (Panasonic, model PV-GS50S, Manaus (Brazil), with capacity of acquisition of $60 \mathrm{~Hz}$, compatible with movement frequency, was fixed to a tripod, and placed in sagittal plan in the cranium-caudal direction of the right side of each animal at a distance of four meters for recording the movements. A two- dimensional space was established for the gait $(3 \times 1 \mathrm{~m})$.

The video calibration was made with the filming of four reflexive targets fixed in a picture measuring (1x1) for recognition of the coordinates $(\mathrm{X}, \mathrm{Y})$ in the tested space.

The Peak Motus 32 system, one of the instruments of Kinemetry (Peak Performance Technologies Inc., Denver, CO., USA) was utilized to register the positioning and displacement of the corporal segments in distinct phases of the movement starting, from the marking of the articulate points of interest.

To control the acquisition, reading, digitalization, treatment, storage of the kinematics parameters and synchronization of data it was used the Software Peak Motus 32 (Marsolais et al. 2003, Peak Performance Technologies Inc., Denver, CO, USA) developed by the Peak Performance Technologies, Incorporation are used.

The $3 \mathrm{M}$ adhesive reflexives markers were placed on the animals using the correct adhesive glue. The anatomical marks were previously trichothomized. These markers identify a point in the space, highlighting the image in a dark environment with a light beamed on them.

Procedures. The markers, measuring approximately two $\mathrm{cm}$ of diameter, with exception of the metacarpal and metatarsal joints that measured approximately one cm of diameter, were placed in set anatomical marks located by inspection and palpation by the same researcher in the right hemi body of each animal (Hottinger et al. 1996).

The determined anatomical points were: shoulder joint: the bigger tubercle of humerus; elbow joint; the lateral humerus epicondyle; carpal joint: styloid process of ulna; metacarpal phalanges joint: the head of the fifth metacarpal; iliac crest; hip joint: greater trochanter of the femur; knee joint: Femoral condile; Tarsal joint: lateral malleolus; Metatarsal phalanges joint: the head of the fifth metatarsal; in the medial aspect of the left side of the dog marks were placed in the metatarsal and second metacarpal of the left limb and in the sagittal crest of the skull (dorsal view).

Acquisition of signals: for the collection of the kinematic data there was the necessity of calibration of the space in which the study was be carried out. It was necessary to introduce and to film an object calibrating with known coordinates. The extension of the calibrated space was of basic importance since the reconstruction methods are more precise within the calibrated space (Nigg \& Cole 1994). 
Each animal walked within the calibrated space, led by the researcher for ten to fifteen attempts and had its speed controlled by direct measurement, with the chronometer.

A light reflector was used to increase the illumination of reflexives marks placed in the anatomical points of each animal. The movement was analysed in the transversal plane, by means of a two-dimensional analysis, with the utilization of a single camera, placed perpendicularly to the plane studied.

Processing - Capture. This process consists of carrying the images captured by the camera to software for analysis. Three of the fifteen registered images of each animal were selected aleatory for the study and an average of these three images was attributed to the animal. Digitalization: Is a slow and exhausting process for the examiner that consists of manually determining the two- dimensional coordinates of the points of interest for reconstruction of the trajectory of each. Each articulated point determined with reflexive marks was digitalized during the six steps; three stride of each animal, totalizing approximately 285 pictures per video, in a defined space of three square meters at speed of $0.85 \mathrm{~m} / \mathrm{s}$. Three videos were digitalized for each studied animal.

Statistical analysis. The normality tests were conducted by The Kolmogorov-Smirnov Method. It was applied in order to verify the values related to each variable follow a normal Gauss distribution, considering a reliable degree of 95 and $\alpha=0.05$ (Fig.1).

\section{RESULTS}

\section{Biometric data, step and stride analysis}

Data Biometric are displayed in Table 1, where we can see the measurement data of the forelimb, hindlimb and thorax of the animal circumference. Analyses were also performed last step and stride, data shown in Table 2.

\section{Dynamic of angular joints}

Each joint showed characteristic patterns of flexion and extension joint, peak flexion, reducing the angle formed by the joint segments that have occurred in the swing phase, the increase of the angle joint, length, was phases of sup-

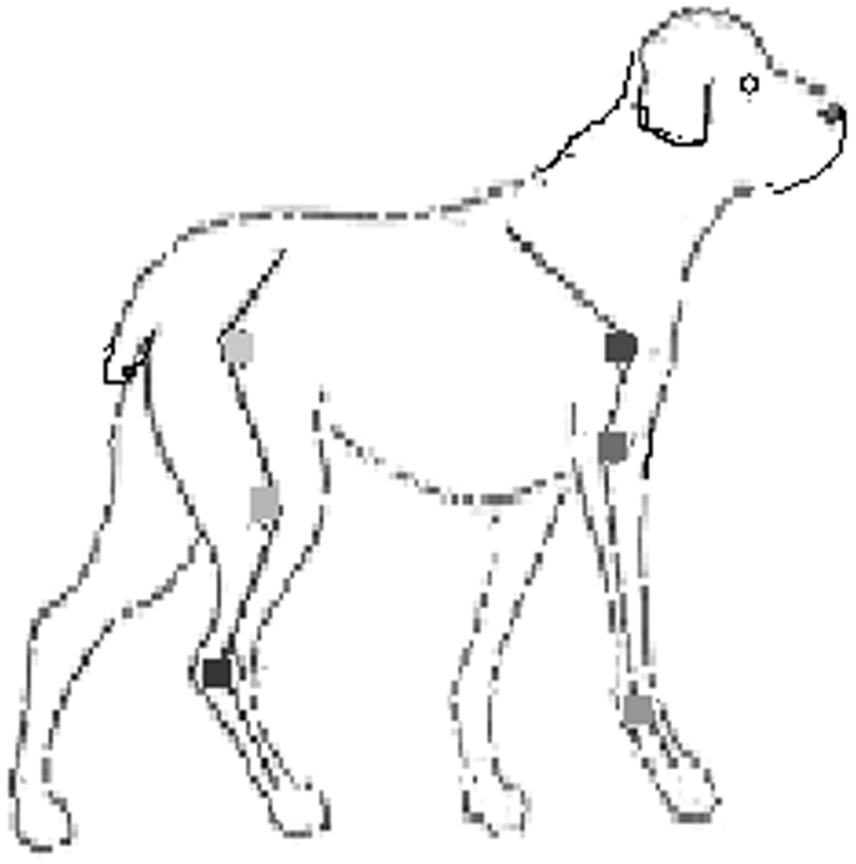

Fig.1. Analysed joint angles.
Table 1. Means of the values of the morphometric data of the seven studied dogs

\begin{tabular}{lcccc}
\hline Variable & Unity & Mean & $\begin{array}{c}\text { Standard } \\
\text { deviation }\end{array}$ & p value \\
\hline Step length of forelimb & {$[\mathrm{cm}]$} & 40,040 & 2,653 & 0,150 \\
Stride length of forelimb & {$[\mathrm{cm}]$} & 79,630 & 4,815 & 0,150 \\
Height of stride of forelimb & {$[\mathrm{cm}]$} & 6,030 & 1,504 & 0,150 \\
Step length of hindlimb & {$[\mathrm{cm}]$} & 39,350 & 1,921 & 0,150 \\
Stride length of hindlimb & {$[\mathrm{cm}]$} & 77,520 & 3,433 & 0,150 \\
Height of stride of hindlimb & {$[\mathrm{cm}]$} & 6,737 & 1,055 & 0,150
\end{tabular}

Table 2. Means of the values of step and stride of the seven studied dogs. For each dog six steps and three strides by video had been analyzed, totalizing eighteen evaluated steps and nine strides for each dog

\begin{tabular}{lcccc}
\hline Variáble & Unity & Mean & Standard deviation & $p$ value \\
\hline Humeral & {$[\mathrm{cm}]$} & 18,710 & 0,756 & 0,150 \\
Ulna & {$[\mathrm{cm}]$} & 18,860 & 0,945 & 0,150 \\
Carpus & {$[\mathrm{cm}]$} & 5,786 & 0,393 & 0,150 \\
Femur & {$[\mathrm{cm}]$} & 19,710 & 0,906 & 0,150 \\
Tibia & {$[\mathrm{cm}]$} & 19,070 & 1,272 & 0,150 \\
Tarsus & {$[\mathrm{cm}]$} & 11,140 & 0,627 & 0,150 \\
Chest & {$[\mathrm{cm}]$} & 70,430 & 2,457 & 0,150 \\
Height & {$[\mathrm{cm}]$} & 55,210 & 0,951 & 0,150 \\
Weight & {$[\mathrm{Kg}]$} & 23,260 & 1,919 & 0,150
\end{tabular}

Table 3. Mean of the values of the joints angles of seven studied dogs.

\begin{tabular}{lcccc}
\hline Variable & Unity & Mean & $\begin{array}{c}\text { Standard } \\
\text { deviation }\end{array}$ & p value \\
\hline Carpal - swing phase & [degrees] & 97,990 & 9,435 & 0,093 \\
Carpal - propulsion phase & [degrees] & 203,800 & 5,966 & 0,150 \\
Carpal - stance phase & [degrees] & 204,500 & 6,676 & 0,150 \\
Elbow - swing phase & [degrees] & 77,670 & 9,704 & 0,068 \\
Elbow - propulsion phase & [degrees] & 127,900 & 6,976 & 0,150 \\
Elbow - stance phase & [degrees] & 116,600 & 8,136 & 0,029 \\
Shoulder - swing phase & [degrees] & 107,800 & 12,170 & 0,150 \\
Shoulder - propulsion phase & [degrees] & 122,000 & 14,060 & 0,104 \\
Shoulder - stance phase & [degrees] & 133,100 & 12,400 & 0,060 \\
Tarsal - swing phase & [degrees] & 120,000 & 4,353 & 0,150 \\
Tarsal - propulsion phase & [degrees] & 154,700 & 4,508 & 0,150 \\
Tarsal - stance phase & [degrees] & 144,200 & 3,593 & 0,150 \\
Knee - swing phase & [degrees] & 102,600 & 7,323 & 0,150 \\
Knee - propulsion phase & [degrees] & 133,500 & 4,772 & 0,150 \\
Knee - stance phase & [degrees] & 143,000 & 6,262 & 0,150 \\
Hip - swing phase & [degrees] & 103,700 & 10,150 & 0,150 \\
Hip - propulsion phase & [degrees] & 137,700 & 8,567 & 0,150 \\
Hip - stance phase & [degrees] & 118,300 & 9,374 & 0,031 \\
& & &
\end{tabular}

* Values of the sample that do not follow a normal distribution $(\mathrm{p}<0.05)$.

port and propulsion of the limb. Analysing the same sequence of steps of the same subject noticed an increase of up to 10 degrees of the same joint (Table 3).

Among the data shown in Table III the shoulder joint was the one that showed variation among dogs in the swing phase the mean peak flexion was 107.82 \pm 12.17 degrees. In all animals studied the peaks occurring in the extension phase support, but the angle difference ranging from 1 degree to 22 degrees from one phase to another. (Fig.2A)

The hip joint showed variations among dogs examined primarily in swing phase, the average was 103.65 degrees \pm 10.14 , peak extension occurred in the propulsion phase 

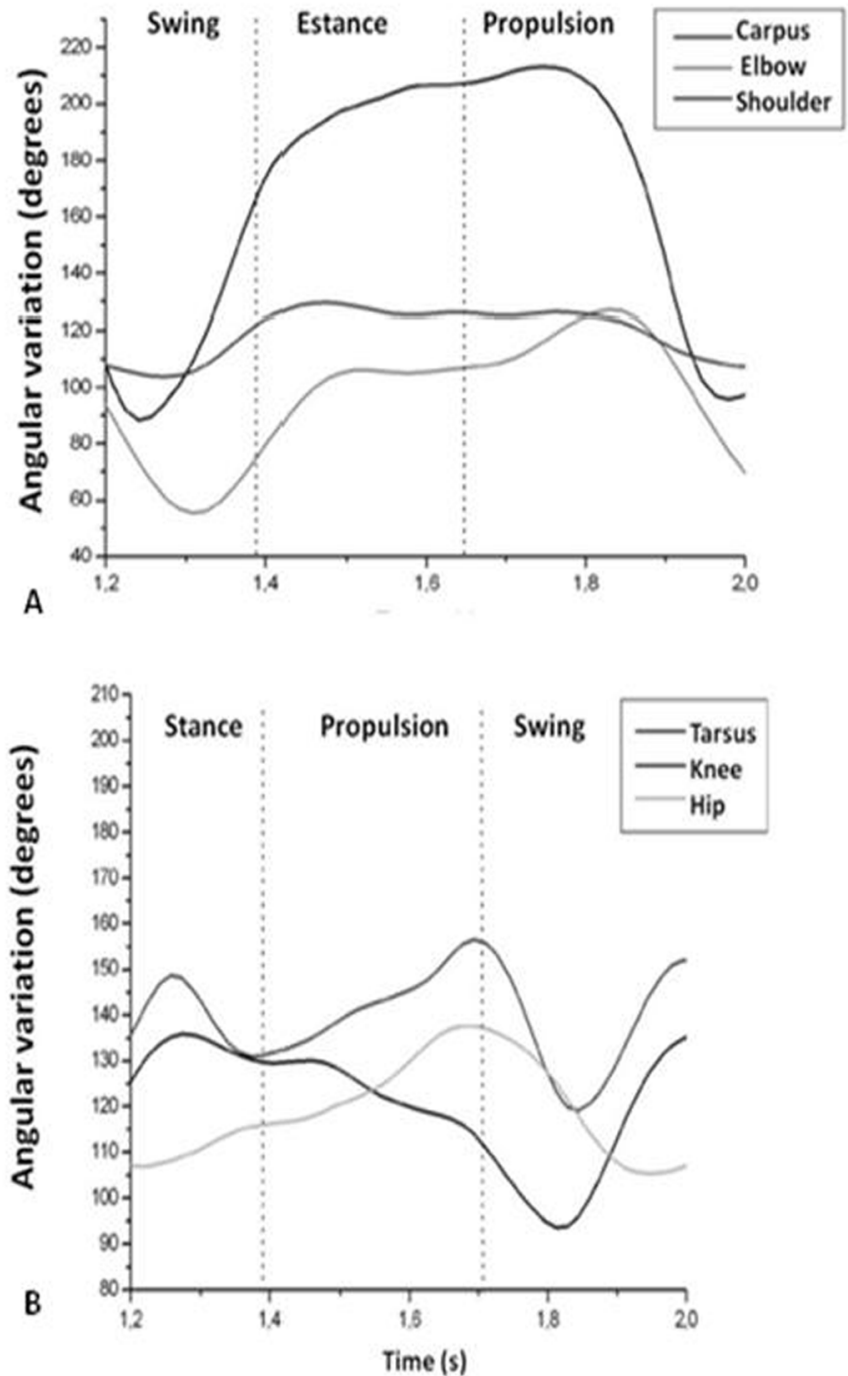

Fig.2. (A) Graph illustrating the articular behavior of forelimbs of golden retriever dog, during periods of swing, stance and propulsion during a stride. (B) Graph illustrating the articular behavior of hindlimbs of golden retriever dog, during periods of swing, stance and propulsion during a strid.

with joint angle of 137,65 degrees \pm 8.56 and stance phase, the average was $118.26 \pm 9.37$ degrees. (Fig.2B)

\section{DISCUSSION}

Biomechanics is a science that deals with biologics system analyses like a multidisciplinary science for the investigation applied of movement, the etiologic factor and phenomenon, indicating the importance of the contribution of each professional, from different areas, in the investigation, facilitating the applicability of the study (Amadio 1999).

The gait analyses of various species occur daily in veterinary medicine. The animal gait is visually evaluated to diagnose and monitor the progression of a disease, however it is a subjective and qualitative analyses, that is, imprecise (Harris 1994, Amadio 1996). It is used to characterize the articular movement in different specimens and breeds, and to compare the articular behaviour of dogs with muscles-skeletal affections and healthy dogs (Nielsen et al. 2003).

The principal objective to be achieved in orthopaedic physiotherapy is the treatment and return to the function, but, for this is necessary to know the normality parameters of a simple population in order to identify the variation, that is, to know the more precise form of the dysfunction of the patients.

This study aimed to establish data of normality of the variables of the gait of healthy golden retrievers dogs and contribute to the comprehension of complex phenomenon of locomotion.

The dogs studied were exclusively Golden Retrievers, because they presents an increasing incidence of muscle skeletical disease, principally the increase of incidence of canine hip dysplasia, furthermore, they are part of the group of dogs that presents hight prevalence of orthopaedics disturbs. This breed is also considered one of the four most populous in the world (Worth et al. 2012).

All the joint movements studied are similar to human movements, except for the elbow canine joint, because when the animal makes a elbow flexion it goes to backwards, decreasing the angle joint, whereas, the human, during the elbow flexion the superior limb is raised to the front of the body, in a closed kinetic chain.

Both the length of the back and lumbar region should be included in the standardization of race, featuring his characteristic gait and better muscle performance optimizing specific functions of each breed, such as running, galloping, etc (Bertram et al. 2000). This indicates that each breed has a characteristic pattern of movement, such flexion-extension, as discussed in this study, as the movements of adduction, abduction and rotation. Many studies about canine gait analysed dogs of different breeds, however, of the same size (Hottinger et al. 1996, Nielsen et al. 2003). Comparative studies between labrador and greyhound breeds, found that differences in hip mechanics are evident, the range of movement of the hind limbs of the Greyhound and stride length were much larger than the values for labrador retriever, clearly indicating that body breed specific factors influence the movement of the animal (Hottinger et al. 1996, Bertram et al. 2000).

The sequence of the members that characterize the stance phase of seven dogs evaluated in this study indicated a lateral gait, where the member distal of one side of the thoracic member performs the same movement of the distal member of the hind limbs homolateral and this sequence is repeated on the contralateral side. These findings are consistent with studies that compare human and animal locomotion, in which the fore and hindlimbs of the dog behave like two independent bipedal members during gait (König \& Liebich 2002).

Comparing the length of the step and stride of thoracic limbs with the length of the step and stride of hind limb, no significant differences were observed, since an affection of a limb can modify these measures, indicating compensation during locomotion. The pelvic limb high of step was slightly higher compared with the height by thoracic limbs and can be attributed to the fact that in quadrupeds the center of 
gravity is located in the thoracic region, or the body burden is not equally distributed, with $56 \%$ of body weight is in the thoracic region and $44 \%$ in the pelvic region.

The present study used a two-dimensional space; other studies of canine gait used two (2D) and three-dimensional (3D) spaces (Colborne et al. 2005, Agostinho et al. 2011). These studies claimed that minor differences are noted between 2D and 3D analyze, many similarities exist between studies in two and three dimensions, such as the joint excursion curves joint and the range of motion, but one must be careful when making comparisons because there is a big difference in technology used for the collection and analysis of data from the studies already published .Can also be observed in studies with three-dimensional analysis kinematics in horses, this analysis has allowed the measurement of the angular range of flexion and extension movement metacaropophalangeal (Back et al. 1993, Bennet et al. 1996, Hottinger et al. 1996, Barrey 1997, Barrey 1999, König \& Liebich 2002).

One possible source of error is the placement error of reflective brands, which can be caused by the displacement of the animal's skin, causing movement of the marks and analysis incorrect interpretation of the results obtained (Van Weeren et al. 1988, 1990, Van den Bogert 2008).

An alternative to this type of problem would be an invasive study with the use of markers directly placed in the bone of the animal, however, two studies on the canine gait in the cranial ligament rupture were made, an invasive and other non-invasive, and the results of the variables analyzed were very similar (Korvick et al. 1994, Decamp et al. 1996, Christovão et al. 2007).

The movements that suffer more changes of displacement of reflective markers are rotational movements. In this study the movements of flexion and extension were approached and all variables have been validated for a normal basis of breed, with the exception of the variables of support the hip and elbow joints, which were not accepted by the hypothesis of normality Kolmogorov-Smirnov method. There are no reports in the literature to explain the variation of these joints during the stance phase of dogs, further studies are needed to clarify these questions (Bennet et al. 1996).

Studies of the joints of the forelimbs and hindlimbs showed a significant variation over the carpal and elbow joints during the swing phase, and the differences are attributed to variations within and between dogs. In addition to displacement during movement of the skin, another possible cause of the variations is the repetition number of analyzes. In this study it was observed that the same animal presents a variation of up to 10 degrees from one cycle to another during operation. This shows that variation exists in the same animal and this change will occur when comparing dogs of the group, leading to the observation of a normal trend that averaged and this average allows the knowledge of the standard of normality (Hottinger et al. 1996).

Despite the morphometric data analyzed not showing any significant physical differences among the dogs examined, visually, the way of walking of, each animal is unique, all the dogs who participated in this study live in the same habitat and have the same habits of life. There is not the hypothesis that a dog is better suited than another to a strange environment, as a laboratory for gait analysis, changing the gait pattern, but it may be noted that some dogs in the study group were more resistant than remaining, which could somehow change a variable studied.

According to the Kolmogorov-smirnov method the hypothesis of normality was accepted for all variables, except for the stance phase of the hip and cubit, assuming a degree of confidence of $95 \%$, that is of significance level $\alpha=.05$.

This study evaluated the propulsive phase of gait in dogs. No similar study has found. Considering that some peaks of articular extension occur at this stage as in the joints of the elbow, hip and tarsus, it is important to analyze this phase of gait, for knowing the functional joint motion, how determined joint performs motion and as this movement will be restricted in an orthopedic disorder. This was the first study to evaluate the gait of healthy golden retriever dogs, giving importance to phases of balance, stance and propulsion and also the analysis step and stride, which represent the first step of movement for further research involving this and other breeds.

Acknowledgements.- We thank the Golden Retriever Muscular Dystrophy (GRMD) Kennel - Brazil, the College of Veterinary Medicine and Animal Science of the University of São Paulo for having ceded the dogs for this study, the team of biomechanical Laboratory of the College Physical Education and Sports of the University of São Paulo for technical support to the study, and CNPq for financial support.

\section{REFERENCES}

Abreu D.K., Ambrósio C.E., Costola-de-Souza C., Alcantara D., Rodrigues E.A.F., Araújo K.P.C., Maiorka P.C. \& Miglino M.A. 2012. Estudo morfofuncional dos rins de cães da raça Golden Retriever afetados pela distrofia muscular (GRMD). Pesq. Vet. Bras. 32:1067-1072.

Amadio A.C. 1999. Introdução à análise do movimento humano descrição e aplicação dos métodos biomecânicos de medição. Revta Bras. Fisioter. 3:41-54.

Amadio A.C. 1996. Fundamentos biomecânicos para análise do movimento humano. Laboratório de Biomecânica - Escola de Educação Física e Esporte da Universidade de São Paulo, São Paulo, p.9-86.

Araújo K.P.C., Bonuccelli G., Duarte C.N., Gaiad T.P., Moreira D.F., Feder D., Belizario J.E., Miglino M.A., Lisanti M.P. \& Ambrósio C.E. 2013. Bortezomib (PS-341) treatment decreases inflammation and partially rescues the expression of the dystrophin-glycoprotein complex in GRMD dogs. PLOS One 8:e61367.

Agostinho F.S., Rahal S.C., Miqueleto N.S., Verdugo M.R., Inamassu L.R. \& El-Warrak A.O. 2011. Kinematic analysis of Labrador Retrievers and Rottweilers trotting on a treadmill. Vet. Comp. Orthop. Traumatol. 24:185191.

Back W., Barneveld A., Van Weeren P.R. \& Van den Bogert A.J. 1993. Kinematic gait analysis in equine carpal lameness. Acta Anat. 146:86-88.

Barrey E. 1997. Locomotion variables, p.72-96. In: Barrey E., Fazio E., Ferlazo A., Lindner A. \& Lopez-Rivero J.L. (Eds), Performance Diagnosis of Horses. Vol.5. Pears, Wageningen, Netherlands. 96p.

Barrey E. 1999. Methods, applications and limitations of gait analysis in horse. Vet. J. 1:1-22.

Bennet R.L., De Camp C.E., Flo G. Hauptman J.G. \& Stajich M. 1996. Kinematic gait analysis in dogs with hip dysplasia. J. Am. Vet. Res. 57:966997.

Bertram J.E.A., Lee D.V., Case H.N. \& Todhunter R.J. 2000. Comparison of the trotting gaits of Labrador retriever and greyhound. Am. J. Vet. Res. 61:832- 38 . 
Christovão F.G., Barros R.M.L., Freitas E.V.V., Lacerda-Neto J.C. \& Queiroz-Neto A. 2007. Análise cinemática tridimensional do movimento de eqüinos em esteira rolante. Arq. Bras. Med. Vet. Zootec. 59:862-868.

Colborne G.R., Innes J.F., Comeford E.J., Owen M.R. \& Fuller C.J. 2005. Distribution of power across the hind limb joints in Labrador Retrievers and Greyhounds. Am. J. Vet. Res. 66:1563-1571.

Decamp C.E., Riggs C.M., Olivier N.B., Hauptman J.G., Hottinger H.A. \& Soutas-Little R.W. 1996. Kinematic evaluation of gait in dogs wit cranial cruciate ligament rupture. Am. J. Vet Res. 57:120-126.

Foss K., Da Costa R.C., Rajala-Schuttz P.J. \& Allen M.J. 2013. Force plate gait analysis in Doberman Pinschers with and without cervival spondylomyelopathy. J. Vet. Intern. Med. 27:106-111.

Gaiad T.P., Silva G.C.A., Silva M.B., Caromano F.A., Miglino M.A. \& Ambrósio C.E. 2011. Physical therapy assessment tools to evaluate disease progression and phenotype variability in Golden Retriever muscular dystrophy. Res. Vet. Sci. 91:188-193

Gerger A.A.C., Souza C.C., Martins D.S., Gaiad T., Brolio M.P., Luppi M.R., Ambrósio C.E. \& Miglino M.A. 2010. Alterações do trato digestório de cães da raça Golden Retriever afetados pela distrofia muscular. Pesq. Vet. Bras. 30:1064-1070.

Grifin T.M., Main R.P. \& Farley C.T. 2004. Biomechanics of quadrupedal walking: how do four-legged animals achieve inverted pendulum-like movements? J. Exp. Biol. 207:3545-3558.

Harris G.F. \& Wertsh J.J. 1994. Procedures for gait analysis. Arch. Phys. Med. Rehabil. 75:216-225.

Hottinger H.A., Decamp C.E.N., Olivier B., Hauptman J.G. \& Soutas-Little R. 1996. Noninvasive kinematics analysis of the walk in healthy largebreed dogs. Am. J. Vet. Res. 57:381-388.

Kane A.M., De Francesco T.C., Boyle M.C., Malarkey D.E., Ritchey J.W., Atkins C.E., Cullen J.M., Kornegay J.N. \& Keene B.W. 2013. Cardiac structure and function in female carriers of a canine model of Duchenne muscular dystrophy. Res. Vet. Sci. 94:610-617.

König H.E. \& Liebich H.G. 2002. Anatomia dos animais domésticos: texto e atlas colorido. Artmed, Porto Alegre. 787p.

Korvick D.L., Pijanowski G.J. \& Schaeffer D.J. 1994 Three-dimensional kinematics of the intact and cranial cruciate ligament- deficient stifle of dogs. J. Biomech. 27:77-87.
Marsolais G.S., McLean S., Derrick T. \& Conzemius M.G. 2003. Kinematic analysis of the hind limb during swimming and walking in healthy dogs and dogs with surgically corrected cranial cruciate ligament rupture. J. Am. Vet. Med. Assoc. 222:739-743.

Nielsen C., Stover S.M., Schulz K.S., Hubbrd M. \& Hawkins D.A. 2003. Two dimensional link segment model of the forelimb of dogs at a walk. Am. J. Vet. Res. 64:609-617.

Nigg B.M. \& Cole G.K. 1994. Optical methods, p.254-286. In: Nigg B.M. \& Herzog W. (Eds), Biomechanics of the Muscle Skeletal System. John Wiley and Sons, New York.

OFA - Orthopedic Foundation for Animals. Disponível em <www.offa.org >

Paster E.R., La Found E., Bury D.N., Triye A., Gregor T.P., Shofer F.S. \& Smith G.H. 2005. Estimates of prevalence of hip dysplasia in golden Retrievers and Rottweilers and the influence of bias on published prevalence figures. J. Am. Vet. Med. Assoc. 226:387-392.

Poy N.S., Decamp J.C., Bennett R.L. \& Hauptman J.G. 2000. Additional kinematic variables to describe differences in the trot between clinically normal dogs and dogs with hip dysplasia. Am. J. Vet. Res. 61:974-978.

Tokuriki M. 1973. Electromyographic and joint, mechanical studies in quadrupedal locomotion: walk. J. Vet. Sci. 35:433-446.

Torres B.T., Moens N.M., Al-Nadaf S., Reynolds L.R., Fu Y.C. \& Bubsberg S.C. 2013. Comparison of overground and treadmill-based gaits of dogs. Am. J. Vet. Res. 74:535-541.

Van den Bogert A., Van Weeren P. \& Schamhard H.C. 1990. Correction for skin displacement errors in movement analysis of the horse. J. Biomech. 23:97-101.

Van Weeren P., Van den Bogert A.J. \& Barneveld A. 1988. Quantification of skin displacement near the carpal, tarsal and fetlock joints of the walking horse. Eq. Vet. J. 20:203-208.

Van Weeren P.R., Van den Bogert A.J. \& Barneveld A. 1990. Quantification of skin displacement in the proximal parts of the limbs of the walking horse. Eq. Vet. J. 9:110-118.

Wingfield C.H.T. \& Stead A.C. 1993. Canine kinematics hindleg gait analysis using a microcomputer. J. Small Anim. Pract. 34:319-324.

Worth A.J., Bridges J.P., Cave N.J. \& Jones G. 2012. Seasonal variation in the hip score of dogs as assessed by the New Zealand Veterinary Association Hip Dysplasia scheme. N. Z. Vet. J. 60:110-114. 